\title{
The impact of overseas training on curriculum innovation and change in English language education in Western China
}

Article

Accepted Version

Li, D. and Edwards, V. (2013) The impact of overseas training on curriculum innovation and change in English language education in Western China. Language Teaching Research, 17 (4). pp. 390-408. ISSN 1477-0954 doi:

https://doi.org/10.1177/1362168813494124 Available at https://centaur.reading.ac.uk/33149/

It is advisable to refer to the publisher's version if you intend to cite from the work. See Guidance on citing.

Published version at: http://tr.sagepub.com/content/early/2013/07/05/1362168813494124

To link to this article DOI: http://dx.doi.org/10.1177/1362168813494124

Publisher: Sage

All outputs in CentAUR are protected by Intellectual Property Rights law, including copyright law. Copyright and IPR is retained by the creators or other copyright holders. Terms and conditions for use of this material are defined in the End User Agreement. 


\section{CentAUR}

Central Archive at the University of Reading

Reading's research outputs online 


\section{The impact of overseas training on curriculum}

innovation and change in English language

\section{education in Western China}

Daguo Li ${ }^{1}$ and Viv Edwards ${ }^{1}$

1 University of Reading, UK

Corresponding author

Daguo Li, National Centre for Language and Literacy, University of Reading,

4 Redlands Road, Reading RG1 5EX, UK.

Email: $\underline{\text { d.li@reading.ac.uk }}$

Tel: 00441183782703 


\section{The impact of overseas training on curriculum}

\section{innovation and change in English language}

\section{education in Western China}

Daguo Li ${ }^{1}$

Viv Edwards ${ }^{1}$

1 University of Reading, UK

\section{Abstract}

This paper assesses the impact of a UK-based professional development programme on curriculum innovation and change in English Language Education (ELE) in Western China. Based on interviews, focus group discussions and observation of a total of 48 English teachers who had participated in an overseas professional development programme influenced by modern approaches to education and ELE, and 9 of their colleagues who had not taken part, it assesses the uptake of new approaches on teachers' return to China. Interviews with 10 senior managers provided supplementary data. Using Diffusion of Innovations Theory as the conceptual framework, we examine those aspects of the Chinese situation which are supportive of change and those which constrain innovation. We offer evidence of innovation in classroom practice on the part of returnees 
and 'reinvention' of the innovation to ensure a better fit with local needs. The key role of course participants as opinion leaders in the diffusion of new ideas is also explored. We conclude that that selective uptake of this innovation is under way and likely to be sustained against a background of continued curriculum reform in China.

\section{Keywords}

English Language Education, secondary school teachers, China, cultural adaptation, diffusion of innovation

\section{Introduction}

The past decade has witnessed a national drive to reform and modernise education in China. Foreign language education, particularly English Language Education (ELE), is at the forefront of this reform movement. The role of teachers in implementing innovation and improving standards has been accorded increasing importance. There have been various funded programmes, at national and local levels, to promote continuing professional development (CPD) for English language teachers in primary and secondary schools both in China and overseas.

In this article, we draw on the views and experiences of participants from the western provinces of China in an ongoing professional development programme 
offered at a British University in order to examine the impact of overseas training on curriculum innovation and change in the relatively less developed region of Western China . In particular, we use the Diffusion of Innovations Theory (Rogers, 2003) as a conceptual model to understand how innovative approaches to second language pedagogy are being adopted in the participating teachers' schools on their return to China. In order to contextualise our study, we will first present an overview of the policy contexts in China and issues around second language pedagogy and then a brief explanation of the main tenets of the Diffusion Model.

\section{Curriculum reform in China}

The first decade of the 21st century can be described as a period of innovation and change in education in China (Hu, 2002, 2003, 2005a, 2005b; Wang, 2007, 2010). Important features of this reform movement are the desire for quality, innovation and the gradual move from a deep-seated preoccupation with the examination driven curriculum as evidenced, for instance, both in daily

education discourse in China and national policy documents such as the National Medium-to-Long-Term Plan for Education Reform and Development (Guo jia zhong chang qi jiao yu gai ge he fa zhan gui hua gang yao) (Xinhua News, 2010).

Curriculum innovation and change in ELE are the defining features of this reform movement. Of particular note are the two new curricula, the 2001 National English Curriculum Standards and the 2003 National English Curriculum 
Standards for Senior Middle School ('The New Curricula' for short) (Wang, 2007, 2010). The New Curricula emphasise student development through language education, with the ultimate goal of developing an 'overall ability in language use' (Wang, 2007, pp. 96-97). This 'overall ability in language use' includes five components: knowledge of the language (e.g. phonetics, grammar, vocabulary); skills in using the language (e.g. listening, speaking, reading, writing); cultural understanding (e.g. knowledge, understanding and awareness); affective development (e.g. international perspective, motivation, confidence), and cognitive development (e.g. learner strategies). In other words, the new curricula emphasise not only linguistic knowledge but also social, cultural and individual aspects of language learning and puts students at the centre of second language pedagogy. The new curriculum reflects the gradual shift in second language acquisition and pedagogy over recent decades from a preoccupation with methods of teaching to a greater focus on teaching and learning. Within this broader perspective, the process of learning and the learner's role in this process have been accorded due importance. The emphasis on competence in language use and the process of learning is also in line with modern 'innovative' approaches to second language teaching, particularly Communicative Language Teaching (CLT) and Task-Based Language Teaching (TBLT) (see also Butler, 2011). Such developments are by no means recent: the 1993 National Curriculum for English was already explicit in its endorsement of the communicative orientation of ELE (Wang, 2007). However, innovation, particularly in the secondary school sector, has often met with resistance and has been the subject of continuing debate (e.g. Hu, 2002, 2005b; Liao, 2004). 
The New Curricula mark a significant expansion on, or a shift of focus from, traditional approaches which rely heavily on a pedagogical model of knowledge transmission with teachers closely following a prescribed authoritative textbook. On the one hand, the nature and extent of teacher receptivity to modern approaches to ELE should not be underestimated. The vast majority of teachers surveyed (over 90\%) in Wang (2007) welcomed the change in conception and approach to teaching advocated in The New Curricula, which embed many principles of CLT. In a study of British Council teacher training partnerships with Chinese universities, Gu (2005, p. 291) offers evidence of Chinese teachers' 'openness to CLT methodologies and a willingness to change and improve their teaching practice'; almost all teachers participating in the study reported that the training offered by the British specialists had allowed them to appreciate that there were other approaches to teaching. But on the other hand, departing from more traditional mainstream approach and implementing innovative policy and change in ELE inevitably poses many challenges. Many of the teachers surveyed in Wang (2007) also experienced feelings of uncertainty and anxiety, as is the case with educational change in general (Fullan, 2001). In addition, implementation of innovation and change entails a good understanding of the change process and enhanced competence on the part of teachers. Appropriate levels of training and support for teachers' professional development is key (Butler, 2011; Wang, 2007). In fact, teacher training is an area given high priority in China (Adamson \& Morris, 1997; Hu, 2002). Various initiatives, both at the national and local levels, have offered teachers opportunities for further professional development. For example, short training courses for key teachers organised at the provincial level in the early 2000s (e.g. Guizhou in Southwest 
China) and the more recent national drive to train teachers, particularly those from rural areas (Ministry of Education \& Ministry of Finance, 2010). Some of these teacher training programmes take place in China, often as collaborative projects involving ELE specialists from overseas and Chinese colleagues (e.g. Gu, 2004, 2005; Yan, 2008). Others take place overseas. For example, there have been numerous short teacher development courses of varied lengths for Chinese teachers in the UK, Australia, the US, Canada and New Zealand (e.g. Conway \& Richards, 2007), although there seems a lack of published research on them. In this paper, we focus on one such a programme at a British university.

\section{Context of the present study}

The British university has been offering three-month courses for teachers of English since 2003 in collaboration with the China Scholarship Council (CSC), a non-profit organization working closely with the Ministry of Education. The courses target six provinces (Gansu, Guizhou, Qinghai, Shaanxi, Sichuan, and Yunnan), five autonomous regions (Guangxi, Inner Mongolia, Ningxia, Tibet, and Xinjiang), and one municipality (Chongqing), which comes directly under Central Government control, and form part of China's Great Western Development Strategy ${ }^{1}$.

The course programme consists of the following five components: second language teaching methodology, language development for the participants, a cultural programme, placement in local British schools, and regular group 
tutorials. In addition, the course participants are accommodated in local British host families. The rationale for the course design is as follows: second language teaching methodology, a main component of the programme, aims to help enhance participants' knowledge and understanding of current theory and practice in ELE. It uses training materials which have been specifically designed for this target audience and are constantly being updated both to respond to ongoing feedback from participants and to reflect the latest developments and good practice both in education more generally and in the subject area (e.g. use of engaging tasks, songs, stories, projects and games). The approach to training, like many other teacher education and professional development programmes in the English-speaking world is largely based on constructivist principles: it is student-centered, interactive, and inquiry-oriented. Theories are embedded as much as possible in practical tasks and activities to suit the audience (secondary school teachers of English). The training programme features both experiential learning and loop input. In experiential learning, trainees or participants temporarily suspend their role as trainee teachers and experience tasks and activities as language students and then discuss and reflect on both the content and process involved. Loop input is 'a specific type of experiential teacher training process that involves an alignment of the process and content of learning' (Woodward, 2003, p. 301). This flexible and eclectic approach can be characterised as post-communicative or task-based, defined by CRAMLAP (2006) as taking 'a more constructivist view of learning emphasising personal learning and discovery on the part of the learner, with more task-based, collaborative work between learners, and a more facilitating role for the teacher.' The language development sessions and cultural programme, complemented by 
accommodation in host families, aims to enhance participants' linguistic skills and cultural understanding by immersing them in real life situations. The placement week in local mainstream British schools allows the participants to both observe and experience teaching and learning in the classroom in a different educational system. It aims to help participants gain an insight into what could be called 'principles in practice' - the contextualization of the theories and principles (e.g. constructivist learning theories and motivation) explicated on the course. Among the distinctive features of the programme are the comprehensiveness of the package, the extended authentic immersion experience, and the strong academic and pastoral support offered to the Chinese teachers by a team of British and Chinese colleagues. The programme aims to provide an enriching CPD experience for the Chinese teachers, enabling them to develop not only a rich repertoire of practical pedagogical skills, techniques and activities but also a deeper understanding of the rationale behind such practices, thus making the link between theory and practice. Such an understanding is often strengthened by their social and cultural experience outside of the classroom. At the time of the present study, 15 courses had been completed by just over 500 participants. To help understand the impact of the courses on the teachers' practice in China, we feel the Diffusion of Innovations Model offers a useful theoretical framework, which will be discussed below.

\section{Diffusion of Innovations}

The Diffusion of Innovations Model, first proposed by Rogers in the 1960s and 
tested in several thousand studies over subsequent decades (Robinson, 2009), identifies several dimensions of fundamental importance in understanding the process of change. The first concerns the different stages. In the knowledge stage, individuals are exposed to an innovation but lack information. In the persuasion stage, they seek more information. Advantages and disadvantages are assessed during the decision stage where the innovation is either adopted or rejected. During the implementation stage, the innovation is employed and its usefulness determined. Finally, in the confirmation stage a decision is made to continue using the innovation.

A second strand concerns the characteristics that determine the success of any innovation. Relative advantage relates to the extent to which an innovation offers an improvement on what went before. Compatibility concerns whether the innovation sits comfortably with existing values and practices. Simplicity and ease of use affect an individual's willingness to adopt the innovation. Trialability concerns an individual's ability to experiment with the new approach.

Observability refers to the extent to which an innovation is observable to others.

The model also outlines the different categories of people involved in change. Innovators are the first to adopt an innovation. Early adopters are opinion leaders who understand that judicious choice of innovation may help them maintain their social standing. The early majority adopts an innovation after varying amounts of time. The late majority follows after most people have adopted the change. Laggards are the last to adopt an innovation. 
Two other features of the Diffusion model can usefully be mentioned at this point. The first concerns the importance of opinion leaders in innovation, particularly in peer-to-peer conversations and peer networks. The second concern the role of 'reinvention' as those responsible for implementing change refine the innovation to meet the needs of risk-averse colleagues.

These various theoretical constructs, some of which are largely absent in the literature on innovation in ELE (see Waters, 2009), will be used to interpret responses to innovation observed in the study schools. For instance, in terms of the Diffusion of Innovations Model, these teachers could be characterised on arrival as early adopters, who had been at the persuasion stage at the start of the UK based course. End of course evaluations, however, suggested they had made the transition to the decision phase, with positive attitudes towards both social constructivist approaches to learning and modern ELE methodologies. We were therefore interested to explore the extent to which they could be characterised at varying lengths of time after their return as having progressed to either the implementation or confirmation stages; we were also interested in gathering evidence of where their non-participating colleagues could be placed along this continuum. Specifically, we sought to answer the following research questions:

1. To what extent had the former participants been able to implement innovation and change in pedagogical practice?

2. To what extent had they attempted adaptation or localization of the innovative approaches?

3. Was there evidence of cascading to their non-participating colleagues 
both in their own school and beyond?

As such, our findings are informed by and have implications for theories of the diffusion of change and models of CPD (Edwards \& Li, 2011). Inevitably, however, our study also aims to contribute to the ongoing debate on second language methodology.

\section{Methodology}

Participants were located through a mixture of purposive and opportunity sampling. The researchers set out the main parameters: we identified schools so as to ensure a good geographical spread (e.g. a balance of metropolis and smaller cities), and specified that we wanted to involve both participant and nonparticipant teachers as well as head teachers and heads of departments. The short time available for fieldwork - ten days in total - placed important constraints on what we could achieve. For this reason, operational details were determined by the CSC in consultation with local education authorities and individual schools. Four cites (Guiyang, Zunyi, Chongqing and Chengdu) in two provinces and one municipality under direct central government control in Southwest China were finally chosen for the field work.

We used three main methods of data collection: interviews, focus groups and classroom observations (see Table 1). We felt these methods were most suited to the purpose of the present study. They would enable us to obtain multiple 
perspectives from different parties closely involved in the innovation process and to actually observe what was happening in the classroom. Our aim was to achieve an in-depth understanding of the impact of the UK programme on the implementation of curriculum innovation in China.

[Insert Table 1 about here]

We conducted open ended, semi-structured interviews with former participants, head teachers and heads of the English Departments in schools in Zunyi, Chongqing and Chengdu, all of whom can be considered early adopters of curriculum reform which includes modern approaches to ELE. The interviews took place in the respondents' offices or the school's conference rooms. Interviews with former participants and heads of the English Departments typically lasted about 30 minutes whereas those with the head teachers lasted between 10 to 15 minutes. Issues explored during the interviews with former participants included: direct or practical methodological aspects of impact; conceptual or attitudinal change; change in capacity (e.g. linguistic competence and cultural awareness); leadership in CPD; support for change, and evidence of (indirect) impact on students.

Issues discussed with the heads of the English departments and head teachers covered the following: expectations by the department (or the school) of the returnee teachers; contribution by the returnee teachers to CPD in the 
department or the school; , the level of support provided to the returnees by the department or school; attitudes towards the returnee teachers; the management of change; and the impact of the overseas training.

We conducted focus group discussions with two different groups: colleagues who had not taken part in the programme from the English Departments in the Zunyi and Chongqing schools (early majority adopters); and a wide range of former participants from across the region who had responded to an invitation from CSC to join us in the following four locations: Guiyang, Zunyi, Chongqing, and Chengdu (early adopters). Issues explored with the non-participant groups included their observation of innovation and change in the practice of their overseas returnee colleagues and their own CPD needs and aspirations. With the former participants, focus group discussions explored issues similar to those covered in individual interviews.

Finally, we observed the classes of five former participants and two nonparticipants in the Zunyi and Chongqing schools, focusing on classroom methodology (e.g. classroom interaction, activities and techniques). One lesson of each of these teachers was observed, which lasted between 45-50 minutes.

By triangulating both the methods used (interviews, focus groups and observation) and the sources of information (participant and non-participant teachers and members of the senior management team), our aim was thus to increase the validity of our findings. 
It was explained clearly to each respondent at the beginning of the data collection session, whether it was an interview, focus group discussion, or classroom observation, and that the purpose of the research was to understand what happened when the Chinese teachers had returned to teaching after their training in the UK. Thus, we made it clear that our interest was not in evaluating the training programme but rather in trying to understand the impact of the UKbased programme on the teachers' practice. We were acutely aware of the potential disadvantages of our 'insider' status as researchers trying to assess the impact of a course that we played an important role in designing and delivering. In order to minimise the effects of researchers' involvement in the design and delivery of the UK course, the interviews with the teachers in the Zunyi and Chonqing schools and focus group discussions with the former participants in Chengdu were undertaken by a research assistant unknown to the participants in the study. Daguo Li was responsible for the interviews with the head teachers and heads of English Departments and focus group discussions with nonparticipants. Although at the request of the CSC he was jointly responsible with colleagues from the CSC for four of the five discussions with the wider groups of former participants, similar patterns of responses from all respondent groups indicated that his involvement had not affected participants' willingness to comment openly and frankly. Because the data collection was undertaken by Chinese native speakers, cultural issues that might have arisen in interviews either in English or with English speakers were avoided.

Focus group discussions and interviews were audio-recorded and transcribed and classroom observations were recorded using field notes. Data were then 
imported into NVivo8 (a specialist software package for qualitative research) for systematic analysis. Analytical categories were allowed to emerge from, rather than being imposed on, the data. A random selection of the categories were scrutinised by two other researchers independently and there was a general consensus on the categories. ${ }^{2}$ To ensure the anonymity of participants, pseudonyms are used throughout in the present article.

\section{Findings}

The main findings concerning pedagogical innovation in ELE are presented under three main headings which relate to the research questions: the evidence for the implementation of new ideas on teachers' return to China; the ways in which new methods were adapted to fit local expectations; and the extent to which these innovations impacted on colleagues who had not participated in the overseas courses.

\section{Implementation}

Curriculum reform in China is clearly influenced by social constructivist principles, including an emphasis on student-centred and communicative and task-based language teaching. As such, it presented new challenges for teachers, most of whom were either at the knowledge or persuasion stages at the start of 
their overseas professional development. The course at the British University offered opportunities for participants to think about how to meet these challenges and make the shift to the decision stage. There was clear and consistent evidence, irrespective of the period which had elapsed since the time spent overseas, that all participants were now involved in implementation. Two recurrent themes emerged from interviews and focus group discussions: differences in perceptions of the nature of learning which framed teachers' approach to teaching and the deployment of specific practices associated with good practice in education or modern approaches to ELE.

In relation to the first theme, teachers offered many examples of transition from authority figure to supporter, guide, and motivator. According to Wang Ling, for instance, 'Before I went on the course, basically there had been more theoretical stuff and teachers tended to dominate. Upon return, students did more and we teachers became a guide'. There was also evidence of the ways in which teachers were making students the centre of curriculum design and classroom teaching. Dai Han, for instance, described her approach to mixed ability teaching in terms of: 'Respecting students as individuals, as every student is different. Their intelligence, their study habits, and their methods of study are all different'. This approach would appear to be in marked contrast with their practice in China before attending the course in the UK. Reflecting on what he would have done prior to the course, Fan Daoming commented: 'Before I would probably ignore ... those who really did not want to learn. After I returned, I felt there might actually be other reasons why these students did not want to study'. Li Mei described her amazement at her students' imagination and creativity, commenting that if 
students are simply asked to repeat things in order to remember them, they are likely to forget. If, however, they are encouraged to learn through doing, their gains will be more real and sustained. In a similar vein, Wang Ling commented:

I used to spend too much time teaching grammar and imparting knowledge to the students. Now I try to make the learning of English more practical, so that it's a tool. I ask students to practise [using English] more. Before, the students had fewer opportunities to practise [using English].

Other evidence of the shift from knowledge transmission to a more constructivist approach concerned aspects of classroom organization and lesson planning. Frequent reference was made, for instance, to forms of cooperative learning. Teachers reported that group and pair discussions had not only promoted cooperative learning but also improved students' ability to work and think independently. Interestingly, participants such as Wei Wen reported that this approach was effective not only with younger students but also with the more examination oriented senior classes:

For example, a specific aspect of grammar: during revision, I can ask the students to form groups to discuss this first. If students do not understand any aspect of the grammar, they can learn from the stronger students, who can offer help to them. After the students have a better understanding by learning from each other, the teacher can then follow up. 
These changes in teachers' philosophy of, and attitudes towards, teaching and learning represented deeper level changes, as a result of the opportunity provided for 'reculturing' (Fullan, 2001, p. 34) or 'deeper questioning and sustained learning' (p. 36) by the programme at the British University. Such changes were likely to underpin and sustain innovation and change in teachers' classroom practices.

In respect of the second theme - changes in teachers' pedagogical practices - we saw evidence of practical techniques, skills, and strategies introduced on the course now being used in their classrooms. They included, for example, gapped dictation, mind maps, story and song, as well as different approaches to lesson planning and classroom organization.

Gapped dictation offers a useful way not only of teaching listening comprehension but of promoting both the conscious learning and the subconscious acquisition of grammatical structures in a second language (Kidd, 1992). Zang Kezuo also highlighted the usefulness of this new approach to dictation for mixed ability settings:

For the teaching of listening, I can design different tasks with the same material, for three different levels A, B, and C, according to students' levels of language. For the lowest level, I only take out some prepositions; for next level, I only take out some verbs, whereas for the highest level, I 
will probably take out both prepositions and verbs... When I use it in my teaching, it both saves time and caters for mixed abilities.

Many participants mentioned the use of mind maps to help students learn vocabulary more effectively. Similarly, they reported that the use of correction codes as a feedback technique not only helped to engage students and improve their efficiency of learning but also reduced teacher workload. SOARing (Supplement, Omit, Adapt, and Replace), a strategy used for the adaptation and integration of teaching materials (CRAMLAP, 2006) also attracted enthusiastic comments. As both Dai Han, a young teacher in an ordinary suburban Junior Middle School, and Sun Danye, a senior teacher in a key urban school, explained:

The starting levels of our students are relatively low... My students even have difficulty understanding Chinese poems ... I was wondering how I could teach the unit. ... Students had difficulty understanding poems, so I used SOARing. First of all, I tried to simplify the teaching objectives ... I introduced songs ... and achieved excellent results ... [I did] not expect that students would be able to write poems in English... [so] I gave them a topic or a few words [and] the students could produce short poems by filling in blanks, etc. (Dai Han)

For example, SOARing, ... played an important role in my teaching. I used this strategy to adapt the textbook and reflected on it a lot. Later I had an article published in Foreign Language Teaching in Primary and Secondary Schools [an influential academic journal in China]. (Sun Danye) 
Our informal observation based on our extensive experience with Chinese secondary school teachers is that they often lack confidence in material adaptation. The main reason was that, until recently, everybody used to teach the same standard national textbook so that they neither saw the need nor wanted to risk adapting such an 'authoritative' textbook. The practice reported here therefore takes on special significance in the change process and points to the returnee teachers' growing confidence and autonomy.

Participants were equally enthusiastic about teaching strategies which students clearly found very motivating, including stories and songs. Reflecting on his situation, Wang Dawei observed:

There were not sufficient activities for my students. After my return from the UK ... I naturally used stories ... It's a good technique and the students immediately liked it. They immediately got interested ... Once they are interested, you can achieve good results. Even if the weakest students did not understand, they would ask the students sitting next to them what the teacher had just said, or they would ask you directly what it was about. I felt that was very successful.

There was similar enthusiasm for the possibilities opened up by project work. Inspired in particular by placements in UK secondary schools, many of the participants had been encouraging their students to enhance their English language learning through independent investigation: 
I was teaching a unit called New Media. I asked my students to make a blackboard poster based on their own interests. They needed to collect their own materials. And the students did really well. (Hou Meili)

When I came back, I mobilised all the grades [year groups] to participate in projects... On the School Open Day, we displayed a lot of the project work in English by the students. Although they might appear a bit basic and not terribly sophisticated, there was a lot in it worth further exploration. Even our Headteacher was impressed. (Sun Danye)

Interviews, focus group discussions and observation all pointed to the enthusiasm with which a wide range of new approaches were being implemented in schools, though it would be premature on the basis of our data to come to any firm conclusions as to the degree of variation in practice between teachers.

\section{Reinvention}

In confirmation, the last stage of the diffusion process, individuals finalise their decision to continue using the innovation and it is often at this point that they use the innovation to its fullest potential. Unlike other theories of change, the Diffusion Model focuses on the evolution of behaviours that better fit the needs of individuals and groups. The success of an innovation depends on reinvention 
or how well it evolves to meet the needs of risk-averse colleagues. Observation, interview and focus group data included examples of the reinvention of modern approaches in ELE to the particularities of the Chinese situation. As Hüttner, Mehlmauer-Larcher, Reichl and Schiftner (2011) point out in another context: 'Teachers are no longer considered to be merely applying theory to practice, but rather as professionals constructing theory and theorizing their practice'.

The present study revealed awareness of the need to adapt new approaches. Returnee teacher, Zhao Liyan, for instance, described how she had localised ideas and techniques learned on the programme at the British University:

Some of the things I learned ... I felt I could not directly apply them in my classroom really. So I now adapted them a bit, [explaining to my colleagues] why I adapted them this way or that way, what were the levels of my students, what were the characteristics of the textbook, and what my actual teaching situation was like.

The approaches promoted in the New Curricula in China are eclectic. The assumption is that teachers will nurture the skills often associated with the west, such as reasoning, imagination, and creativity, in tandem with the more traditional skills of observation and memorization. Participants on the course at the British University clearly shared this assumption, expressing a desire to integrate more recent international developments with practices traditionally valued in China. To this end, Wan Zhuolin (a mid-career teacher in Chongqing) commented explicitly on the synergy of the traditional and new approaches she 
had used in a demonstration lesson delivered to a large audience as part of inservice training organised by her Municipality:

My approach was to combine ... our traditional teaching methodology, and some of the methods and techniques offered us by Alice [ELT Trainer on the programme] ... The observers felt the lesson was very useful to our students... I felt I directly benefited from Alice's storytelling techniques.

Echoing the observations of writers such as $\mathrm{Hu}$ (2005a), Wu (2001), Yan (2008), and Zheng and Davison (2008), one of the main constraints in implementing change reported by the teachers was the examination system. Wan Ling expressed frustration at her students' weak speaking and listening skills which she considered to be a direct consequence of the need to spend time on examination preparation. The head teachers and heads of English Departments recognised this obstacle, too. One of the head teachers, Mr Cai, offered the following comments:

The only thing is, some advanced pedagogical ideas cannot yet be fully implemented with the current educational situation in China. ... For some students, if you differentiate, some of the things, she [the returnee teacher] can't really do, feeling a bit constrained. This is because of the constraints of the examination regime ... our national examination system, the actual needs of the parents and students and the utilitarian value attached to student progression and Gaokao [the university entrance examination]. These things have to be considered. 
Nonetheless, some participants had found ways of incorporating ideas from the course, even with older students in examination classes, as evidenced by the experience of Fan Daoming, a teacher from a key school in Zunyi:

Probably people all think that Senior Three is really geared towards Gaokao and, with the amount of pressure, it should be pretty difficult to do activities or things like that. But I want to say today - [first author] ... has just observed my lesson - I felt the lesson was quite dynamic for a Senior Three class. I believe, teaching at Senior Middle School, even at Senior Three, we should not abandon activities or some of them. We could motivate our students through activities so that they want to learn and it's not me making them learn.

Our observation of the lesson for Senior Three taught by Mr Fan Daoming attests to his claim. By carefully staging his lesson, e.g. beginning with an English song as a warmer followed by several pair and group work activities, yet with a focus on preparing students for the university entrance examination (e.g. how to get a high mark in writing), and ending with another English song, he seemed to be able to make an otherwise boring review lesson more interesting and engaging. Although this practice was not totally new to him, he commented in the interview that training in the UK had not only given him more confidence in the continued use of the technique but also inspired him to explore new ways. There was evidence across the lessons of returnees that we observed of genuine effort to use or adapt activities (e.g. board games) from the course at the British 
University to encourage student communication and interaction.

\section{The role of peer-to-peer conversations}

The question remains as to whether these innovations are limited to the teachers who participated in the programme or whether they are being integrated in the practice of their colleagues. As Hu (2005b, p. 65) points out, there is no reason to assume that policy imperatives feed through to classrooms in a 'neat, linear, predictable and deterministic manner'. There was a certain level of expectation on the part of the CSC, the local education authorities and individual schools, that returnees would cascade their learning to colleagues whenever and wherever possible. The effectiveness of this approach to training depends, of course, on the levels of understanding achieved by those responsible and their ability to cascade their learning; this model of professional development is therefore by no means unproblematic (Chisolm, 2004).

The responses of teachers who had not taken part in the UK programme suggested that they were at the second and third stages (persuasion and decision) in the decision innovation process. Many of those who took part in focus group discussions spontaneously commented on their frustration with the routine nature of their own teaching. As Prabhu (1990, p. 174) argues, 'The enemy of good teaching is not a bad method, but overroutinisation.' They were clearly impressed by the confidence demonstrated by their returning colleagues, their dynamic approaches to teaching and the rich repertoire of new pedagogical 
ideas or 'tricks' they could draw on from their overseas experience. Ms Yang, who took part in a non-participant focus group, commented:

I can feel it. Their lessons are more 'alive'. They have experienced the authentic language and culture. Just like travel, if you only rely on a tour brochure of a town or city, you can probably only learn a small part of it. But if you really want to learn its history and how it develops, you probably need to go there and see for yourself what it is like. You can learn more by getting into some depth. ... In our textbook, students need to learn about British culture. When we talk about Britain ... those who have been to the UK do not even have to look at the textbook; they can directly relate to their own experience [in the UK] ... I can feel the big difference.

The returnees were clearly opinion leaders. The decision to adopt new approaches inevitably entails a level of risk. It thus seems reasonable to speculate that the enthusiasm of respected teachers may offer reassurance to more risk-averse colleagues.

There was certainly no shortage of evidence of a strong desire on the part of those who had not participated in the UK programme to have a similar opportunity to be exposed to new ways of thinking. A lesson that we observed delivered by Ms Liu, an apparently capable young teacher, was characterised by knowledge transmission and deductive presentation of language knowledge (knowledge of word formation), with a notable absence of interactive activities. 
This approach to teaching was confirmed by her Head of Department who sat in on the lesson, as very typical of Ms Liu. During the follow up focus group, Ms Liu commented on her own lesson and methodology and expressed the desire to be exposed to new ideas, particularly those relating to classroom activities, in order to encourage student interaction and introduce variety to her lessons.

It is difficult to assess from our data the extent to which the non-participant teachers, whose lessons we observed and who contributed to the focus group discussions, were representative of other English teacher colleagues. There was every reason to suppose, however, that such teachers formed part of an early majority of teachers receptive to change. The same openness to change reported in Wang's (2007) survey of teacher responses to the New Curricula and Gu's (2004) and Yan's (2008) study of British Council teacher training partnerships with Chinese universities was also evident in the responses of non-participant teachers in the present study.

Since the main focus of our study was on returnee teachers, far less data was collected from non-participants and the findings in relation to this group thus need to be interpreted with caution. Nonetheless, in attempting to assess the impact of the UK training on classroom practice in China, we find ourselves in agreement with Robinson (2009) who observes:

[T] he adoption of new products or behaviours involves the management of risk and uncertainty. It's usually only people we personally know and trust - and who we know have successfully adopted the innovation 
themselves - who can give us credible reassurances that our attempts to change won't result in embarrassment, humiliation, financial loss or wasted time.

\section{Discussion}

While policy directives are unlikely to feed through to classrooms 'in a neat, linear, and deterministic manner' (Hu, 2005b, p. 65), this study offers ample evidence of the ways in which recent innovations in language teaching methodology are being used productively in schools in China. For instance, teachers who previously felt comfortable following a textbook now have access to more innovative ways of teaching (e.g. using games to cater for different student abilities, adapting materials, and exploring creativity in ELE). Similarly, a sounder understanding of issues in language teaching and learning has increased their confidence. Thus a teacher who had already been using songs before attending the course now had a better understanding of the ways in which this activity could be used to motivate students. Findings of this kind are of particular significance given our focus on the Western provinces where educational reform has tended to lag well behind developments in the large cities and coastal regions $(\mathrm{Hu}, 2003)$.

Of the five qualities that determine success (relative advantage, compatability, complexity, trialability and observability) (Rogers, 2003), three aspects of the Chinese situation predispose teachers to change; two aspects constrain 
innovation. Looking first at the facilitating factors, the evident dissatisfaction of many educators with the effectiveness of English teaching in China and the supportive policy environment can be assumed to positively predispose teachers to new teaching approaches (relative advantage). Two other qualities trialability and observable results - also bode well for innovation. New approaches to teaching permit different levels of experimentation on the part of teachers and therefore entail less risk.

Chinese teachers form strong 'communities of practice' (Lave \& Wenger, 1998), creating opportunities to see the results of innovation and stimulate discussion of new ideas with colleagues. They are organised into teaching research groups composed either of all the teachers of a given subject, or a sub-group of the teachers of a subject for a given year group. Members of a teaching research group do their marking, discuss their teaching and their students, and undertake collective curriculum and lesson planning in a shared workspace or room. As reflective practitioners, they present end-of semester reports on aspects of their teaching at group meetings. They are also regularly involved in observing colleagues' lessons. In addition to these routine teaching and research activities, senior teachers often mentor their colleagues when there are English teaching competitions at both local and national levels to showcase pedagogical skills and promote CPD - an interesting phenomenon which, to our knowledge, is rarely seen in other countries (see Grierson \& Gallagher, 2009, however for a notable exception). 
Other factors - notably, compatibility and ease of use - militate against change. The social constructivist underpinnings of the new approaches to teaching are seriously at odds with traditional values. Similarly, simplicity and ease of use are likely to militate against change, since the innovations in question require teachers to develop new skills and understandings. In a complex situation of this kind, the Diffusion Model would not predict the wholesale, enthusiastic adoption of new methods and this is, indeed, the case. Sufficient conditions are in place, however, to challenge assumptions that the new approaches cannot be adapted for use in the Chinese context. In fact, innovative approaches such as CLT and TBLT have been largely re-interpreted and adapted to fit the local sociocultural realities both in China and the wider Asia-Pacific Region (e.g. Butler, 2011; Littlewood, 2007).

The Diffusion of Innovations Model has wide applicability and has been used in many contexts, including agriculture and medicine. Other theories which focus more specifically on the management of change in education, however, also offer support for the notion that new approaches to language teaching have a place in Chinese classrooms. Robinson and Latchem (2003, p. 239), for instance, identify two conditions which need to be fulfilled if new teaching methods are to become established: first they have to be 'proven in practice'; second, they should be adopted by 'a critical mass of teachers who, together, reinforce each other's beliefs, reduce the risks of innovation and eventually change the culture of teaching'. Central to this process are 'shared goals, a supportive head teacher and a collaborative atmosphere'. In this respect, the critical mass created by the British based programme in the Western Region over nearly a decade is 
significant. It is an important resource on which the returnee teachers can draw as 'communities of practice' in their efforts to implement innovation and change. This is something missing in shorter or one-off programmes (e.g. Conway \& Richards, 2007). Additionally, the organization of Chinese schools can clearly be seen to offer structural support not only for conformity but also for change. It is important to note that, in China, the space necessary for innovation is provided both by top-down policy and by bottom-up 'buy-in' at the level of the school. Such buy-in is facilitated by the strong communities of practice associated with teaching organised around research groups that encourage reflective practice, with ample opportunities to observe and be observed and an emphasis on mentorship by more experienced colleagues.

The present study also has implications for the debate about cultural appropriateness of innovation and, in particular, communicative and task-based approaches to language teaching (see, for example, Pennycook, 1994, 1998; Phillipson, 1992). In the context of such discussions, it is clearly important to avoid the dangers of essentialism. CLT and TBLT are not monolithic methods but ones which have undergone considerable modification over the years in many different parts of the world. It is very rare that any teacher would religiously follow a strong form of these approaches (see for example, discussion in Butler, 2011). There is now a greater appreciation that there is no single, universal method for language teaching and a willingness to incorporate elements associated with other methods, as an enlightened teacher (Brown, 2000) or by encouraging teachers to engage with their sense of plausibility or pedagogic intuition (Prabhu, 1990). The fact that the early history of CLT was associated 
with assumptions of cultural superiority and universal application does not imply that there is nothing of value or relevance to Chinese language classrooms. And while Chinese teachers are indeed influenced by traditional values, this does not mean that they are either unable or unwilling of adopt ideas from other cultures, provided adequate training and support are provided.

An important finding from the present study concerns the reinvention of the new approaches to better fit the Chinese situation. In this respect, we find ourselves in agreement with researchers (see for instance, Delens, 1999; Fullan, 2001; Kennedy, 1988; Leach 1994) who stress the importance of building on - rather than ignoring - teachers' cultural heritage and of promoting 'ownership' of innovation. Harmer (2003, p. 291) neatly summarises this position when he notes that every teacher 'is a product of their culture, their training and their experiences, and this is something to be celebrated not sanctioned'. He further adds that the problem is not methodology per se but how this methodology is adapted to fit the needs of students.

These observations clearly apply to participants in our study. To assume that Chinese culture is static with no room for teachers and students to manoevre would be a serious disservice to all concerned. While traditional practices still seem to predominate (Hu, 2005a; Wang, 2007), there is evidence of willingness to experiment and change. Returnees have identified a range of practices and strategies which they have been able to adapt to their own local circumstances. New approaches introduced as part of their overseas professional development have not, however, been adopted uncritically. On the contrary, teachers have 
been mindful of the constraints within which they work, not least an examination system which has failed to keep pace with curriculum development.

It is important to acknowledge that the issues raised in relation to new approaches to language teaching in our study are not limited to China. Various writers have highlighted the need to culturally embed - or mediate - new teaching practices. Ellis (1996, p. 217), for instance, proposes that, wherever possible, teachers should find 'points of congruence between seemingly contradictory cultural norms' and draws attention to the support for studentcentred teaching offered by the Chinese proverb: 'If you give a man a fish you can feed him for one day, but if you teach him how to fish you can feed him for a lifetime'. In a similar vein, Tan (2005) cautions that communicative activities need to be tailored to suit the cultural needs of students in Singapore. Suggestions include starting with traditional teacher-centered activities such as question-and-answer exercises to elicit short responses from the children, before moving on to more student-centred activities such as role-play and problem solving; or asking children to copy a short list of words which they are going to use later as a bridge to more interactive activities based on these words.

Finally, we need to consider the trustworthiness of our data. We were, of course, mindful of the potential positive image that participants might want to project of their experience. However, it is important to remember that demonstration classes are a well-established feature of professional life in China. It could be argued therefore that Chinese teachers are less likely to modify their behavior when observed than teachers in other settings. There was certainly no 
compelling evidence that the lessons we observed were more 'artificial' than their normal practice. On the contrary, interview data suggested that the techniques and activities observed had already been integrated into the teachers' normal practice. In addition, both interview and observation data pointed to variation in the rates at which innovations had been adopted, as indeed the Diffusion Model predicts.

\section{Conclusion}

Our focus in this paper has been on the extent to which new approaches to language teaching are being applied in the classroom and on the ways in which these approaches are being adapted to meet local needs. By applying tenets of the Diffusion model - and in particular, the stages of the adoption process, the characteristics of innovations that influence the success of an innovation and the notions of 'opinion leader' and reinvention - we have been able to account for many aspects on the current situation in the western provinces of China.

Evidence that returning teachers were implementing innovations introduced as part of their overseas-based professional training included a shift from authority figure to supporter, guide and motivator. Similarly, there were extensive examples of the ways in which teachers were making students the centre of curriculum design and classroom planning, using a variety of practical teaching techniques and strategies. Support from central government policy and senior management enhanced the 'trialability' of their efforts and the ease with which 
they were able to experiment with new methods in the classroom. Teachers varied to some extent, however, in their confirmation of the innovation, with relatively few, for instance, reporting ways of integrating communicative and task-based approaches in the senior examination classes. There was also evidence of the reinvention which marks successful innovation in the form of new approaches localised in response to poor levels of resourcing, large classes, limited teacher proficiency in English and an examination system which is often a poor fit with the expectations of the New English curricula. A new wave of curricular reform in China, however, as exemplified in the recently published English Curriculum Standards for Compulsory Education (Ministry of Education, 2011), to be implemented nationwide from September 2012, is set to change the situation and will offer further policy support for the kind of innovation discussed in the present article.

There was also evidence that these innovations were being cascaded to their colleagues. While recognizing that the principles underlying the new approaches to language teaching may be at odds with principles underpinning traditional classrooms, various aspects of the course programme in the UK and situation in China are supportive of innovation. In the context of the rise of English as a global language, dissatisfaction with the educational outcomes associated with text-based learning has been a catalyst for greater openness towards alternative approaches as embodied at the policy level in the New Curricula.

The organization of teaching in China around research groups and the emphasis on reflective practice are particularly supportive of diffusion, as are the 
demonstration classes and local and national competitions. All point to the observability of the innovation. The decision as to whether to adopt or reject change involves the management of risk and uncertainty. The overseas trained teachers are opinion leaders with considerable influence among their peers. The fact that trusted colleagues have successfully adopted the new methods therefore offers valuable reassurance. Although there is always the risk of resistance to top-down policy reform, there was clear evidence of early majority participation in change. We are mindful, however, that a more accurate assessment of the extent of diffusion would have required a much larger sample of non-participants and a longer period of fieldwork.

\section{Acknowledgements}

We wish to acknowledge the practical support of the China Scholarship Council in organizing access to schools and teachers and the contributions made to the project by Xiaorong Zhang and Dong He.

\section{Funding source}

This work was supported by a British Council English Language Teaching Research Award. 


\section{Notes}

1. The Great Western Development Strategy (Xi Bu Da Kai Fa) was officially launched in January 2000 by the Chinese Government to attract and allocate money and other resources for the development of China's poorer, and historically more neglected, central and western regions. A secondary goal of this strategy is to better develop the ethnic minority areas, which will tie them closer to the rest of China. (See Sims \& Schiff, 2000)

2. Xiaorong Zhang from the University of Reading and Professor Dong He from Guangxi University for Nationalities, China.

\section{References}

Adamson, B., \& Morris, P. (1997). The English curriculum in the People's Republic of China. Comparative Education Review, 41, 3-26.

Brown, D. (2000). Principles of Language Learning and Teaching (4th Edition). Harlow, UK: Longman.

Butler, Y.G. (2011). The implementation of Communicative and Task-Based Language Teaching in the Asia-Pacific Region. Annual Review of Applied Linguistics, 31, 36-57.

Chisolm, L. (ed.). (2004). Changing class education in post-apartheid South Africa. London \& New York: Zed Books. Retrieved from: www.hsrcpress.ac.za/product.php?productid=1937

Conway, C. \& Richards, H. (2007). Meeting the needs of visiting in-service EFL 
teachers from China. The TESOLANZ Journal, 15, 71-87.

CRAMLAP (Celtic, Regional and Minority Languages Abroad Project). (2006). An Overview of Second Language Teaching Methods and Approaches. Retrieved from: www.cramlap.org/Documentation/

Delens, M. (1999). Whose rules apply? Educational project management in less developed countries: cultural considerations. In: F. Leach \& A. Little (Eds.), Education, Cultures and Economics: Dilemmas for Development (pp. 347-369). New York \& London: Falmer Press.

Edwards, V. \& Li, D. (2011). Confucius, constructivism and the impact of continuing professional development of teachers of English in China. British Council Research Papers.

Ellis, G. (1996). How culturally appropriate is the communicative approach? ELT Journal, 50, 213-218.

Fullan, M. (2001). The new meaning of educational change. (3rd Edition). London, UK: RoutledgeFalmer.

Grierson, A.L. \& Gallagher, T.L. (2009). Seeing is believing: creating a catalyst for teacher change through a demonstration classroom professional development initiative. Professional Development in Education, 35, 567-584.

$\mathrm{Gu}, \mathrm{Q}$. (2004). Intercultural experience and teachers' professional development. ELTED, 8, 1-15.

Gu, Q. (2005). The perception gap in cross-cultural training: an investigation of British Council English language teaching projects in China. International Journal of Educational Development, 25, 287-304.

Harmer, J. (2003). Popular culture, methods, and context. ELT Journal, 57, 288294. 
Hu, G. (2002). Recent Important Developments in Secondary English-language Teaching in the People's Republic of China. Language, Culture and Curriculum, 15: 30-49.

Hu, G. (2003). English language teaching in China: regional differences and contributing factors. Journal of Multilingual and Multicultural Development $24,290-318$.

Hu, G. (2005a). Professional Development of Secondary EFL Teachers: Lessons From China. Teachers College Record, 107, 654-705.

Hu, G. (2005b). 'CLT is best for China' - an untenable, absolutist claim. ELT Journal, 59, 65-68.

Hüttner, J., Mehlmauer-Larcher, B., Reichl, S. \& Schiftner, B. (2011). Introduction. In J. Hüttner, B. Mehlmauer-Larcher, S. Reichl \& B. Schiftner (Eds.), Theory and Practice in EFL Teacher Education: Bridging the Gap (pp. xiii-xix). Bristol, UK: Multilingual Matters.

Kennedy, C. (1988). Innovation for a change: teacher development and innovation. ELT Journal, 41, 163-170.

Kidd, R. (1992). Teaching ESL Grammar through Dictation. TESL Canada Journal/Revue TESL du Canada, 10, 49-61.

Lave, J., \& Wenger, E. (1998). Communities of Practice: Learning, Meaning, and Identity. Cambridge, UK: Cambridge University Press.

Leach (1994). Expatriates as agents of cross-cultural transmission. Compare, 24, 217-231.

Liao, X. (2004). The need for communicative language teaching in China. ELT Journal, 58, 270-3. 
Littlewood, W. (2007). Communicative and task-based language teaching in East Asian classrooms. Language Teaching, 40, 243-249.

Ministry of Education (2011). English Curriculum Standards for Compulsory Education. Beijing, China: Beijing Normal University Publishing Group. Ministry of Education \& Ministry of Finance (2010) National Teacher Training Programme. Retreived from: http://www.gov.cn/zwgk/2010$\underline{06 / 30 / \text { content } 1642031 . h t m}$

Pennycook, A. (1994). The cultural politics of English as an international language. London, UK: Longman.

Pennycook, A. (1998). English and the discourses of colonialism. London, UK: Routledge.

Phillipson, R. (1992). Linguistic Imperialism. Oxford, UK: Oxford University Press.

Prabhu, S. (1990). There is no best method - Why? TESOL Quarterly, 24, 161-176.

Robinson, B. \& Latchem, C. (2003). Teacher Education through Open and Distance Learning. London: Routledge.

Robinson, L. (2009). A summary of Diffusion of Innovations. Retrieved from: www.enablingchange.com.au

Rogers, E. M. (2003). Diffusion of innovations (5th Edition). New York, NY: Free Press.

Sims, T. \& Schiff, J. (2000). Special Focus: Your Investment - The Great Western Development Strategy. The China Business Review 2000 Issue. Retrieved from: http://www.chinabusinessreview.com/public/0011/sims.html

Tan, C. (2005). How culturally appropriate is the communicative approach for primary school children in Singapore? The Reading Matrix, 5, 21-35. 
Wang, Q. (2007). The National Curriculum changes and their effects on English Language Teaching in the People's Republic of China. In J. Cummins \& C. Davison (Eds.) International Handbook of English Language Teaching (pp. 87-105). New York, NY: Springer.

Wang, Q. (2010). The Rationale for the National Curriculum Standards for Senior Middle School. In Q. Wang \& X. Zhang (Eds.) An Analysis of the National English Curriculum for Senior Middle School and Implementation Strategies (pp. 1-20). Beijing, China: Beijing Normal University Publishing Group.

Waters, A. (2009). Managing innovation in English language education. Language Teaching, 42, 421-458.

Woodward, T. (2003). Loop input. ELT Journal, 57, 301-304.

Wu, Y. (2001). English language teaching in China: Trends and challenges. TESOL Quarterly, 35, 191-194.

Xinhua News (2010). Guo jia zhong chang qi jiao yu gai ge he fa zhan gui hua gang yao (2010-2020) (National Medium-to-Long-Term Plan for Education Reform and Development (2010-2020)). Retrieved from: http://www.gov.cn/jrzg/2010-07/29/content 1667143.htm

Yan, C. (2008). Mutual adaptation: Enhancing longer-term sustainability of crosscultural in-service teacher training initiatives in China. System, 36, 586-606. Zheng, X. \& Davison, C. (2008). Changing Pedagogy: Analysing ELT Teachers in China. London, UK: Continuum. 


\begin{tabular}{|l|l|l|l|} 
Method & \multicolumn{1}{l}{ No of } & Numbers of focus & \multicolumn{1}{l}{ Numbers of } \\
& interviews & groups & \multicolumn{2}{l|}{ classroom } \\
Former & 10 & 5 (involving a total & 5 \\
participants & & of 48 participants) & \\
\hline Non- & 0 & 2 (involving a total & 2 \\
participants & & of 9 participants) & \\
\hline Headteachers/ & 10 & 0 & 0 \\
Heads of section & & & \\
\hline
\end{tabular}

Table 1: Data collection methods and participants 


\section{Biographies}

Daguo Li (PhD) is Lecturer in Education and Deputy Director of the National Centre for Language and Literacy, the University of Reading. His areas of research are second language learning, professional development for second language teachers, and international education.

Viv Edwards is Professor of Language in Education at the University of Reading where she is also Director of the National Centre for Language and Literacy. She is editor of the international journal, Language and Education, and has published widely in the area of learning and teaching in multilingual classrooms. 
Words: 8713 